\title{
The use of a battery of examination methods for detection of cervical metastases in squamous cell carcinoma of the oral cavity
}

\author{
Jan Stembireka,b, Zuzana Cermakova ${ }^{\mathrm{ce},}$, Michal Kulnigc, Pavel Hurnik ${ }^{\mathrm{d}}$, Jakub Cvek , Kamila Resova ${ }^{\mathrm{e}}$, \\ Tomas Jonszta ${ }^{f}$, Martina Litschmanova ${ }^{g}$, Jiri Stransky ${ }^{a}$
}

\begin{abstract}
Introduction. In patients with squamous cell carcinoma of the orofacial area, the presence of cervical metastases represents a single most significant prognostic factor. This fact underlines the importance of thorough examination of the cervical lymph nodes for potential tumor involvement. To verify this, the most common investigative methods are physical examination (PE), sonography (US) and computed tomography (CT), which have also been used to assess the stage of the disease in the patients in our research.

Objective. To evaluate the performance of individual methods (physical examination, sonography, computed tomography) and combinations.

Method. Patients with squamous cell carcinoma of the oral cavity, who had undergone physical, US and CT examinations at our department followed by radical neck dissection were included in this retrospective study. A total of 57 patients were included.

Results. The sensitivity of PE, US and CT were $38 \%, 69 \%$ and $61 \%$, respectively, however CT+US combination yielded $83 \%$ sensitivity and combination of all these methods $86 \%$ sensitivity. The number of false positives was however relatively high with specificity of the 3 -way combination at $65 \%$.

Conclusion. A combination of our three widely available inexpensive methods detected $86 \%$ of metastases in cervical nodes. The large number of false positives however indicates that the method should rather be used for screening in selecting patients who need additional and more expensive imaging than for diagnosing cervical metastases. Also, as $14 \%$ of cervical metastases pass undetected using our method, we would recommend an additional examination at least by US+PE several weeks to a few months after the initial examination.
\end{abstract}

Key words: squamous cell carcinoma, oral cavity, cervical metastasis, radical neck dissection, sonography, computed tomography

Received: December 16, 2019; Revised: May 28, 2020; Accepted: June 11, 2020; Available online: June 26, 2020

https://doi.org/10.5507/bp.2020.026

(c) 2021 The Authors; https://creativecommons.org/licenses/by/4.0/

${ }^{a}$ Department of Oral and Maxillofacial Surgery, University Hospital Ostrava, Czech Republic

bInstitute of Animal Physiology and Genetics, Czech Academy of Sciences, Czech Republic

'Faculty of Medicine, University of Ostrava, Czech Republic

${ }^{d}$ Department of Pathology, University Hospital Ostrava, Czech Republic

${ }^{e}$ Department of Oncology, University Hospital Ostrava, Czech Republic

fDepartment of Radiology, University Hospital Ostrava, Czech Republic

${ }^{9}$ Department of Applied Mathematics, Faculty of Electrical Engineering and Computer Science, SB-Technical University Ostrava, Czech

Republic

Corresponding author: Jan Stembirek, e-mail:jan.stembirek@iach.cz

\section{INTRODUCTION}

Tumors of the oral cavity followed by tumors of the nasal cavity, paranasal cavities, salivary glands, larynx and pharynx represent a major group of relatively frequent malignancies - the head and neck tumors. This group occupies the 7 th place worldwide in tumor-related mortality. According to the IARC (International Agency for Research on Cancer), the global incidence of the tumors of the oral cavity and lips was in 2012 over 300,000 cases, i.e, approx. $2.1 \%$ of all tumors. The 2012 mortality related to these tumors was just below 150,000. The Age Standardized Incidence Rate according to the world standards (ASRW) was 4 cases per 100,000 population. Both the incidence and mortality in men was approx. twice as high than for women ${ }^{1}$. Squamous cell carcinoma is the dominant type of carcinoma in the oral cavity because most risk factors affect the upper layer of oral mucosa cells. Alcohol and tobacco abuse (including chewing or snuffing tobacco) are the most significant risk factors ${ }^{2,3}$. At least $75 \%$ of the tumors of the head and neck are caused by tobacco and alcohol abuse $\mathrm{e}^{4-7}$. The synergistic effect of these risk factors has also been reported as people abusing both tobacco and alcohol are in higher risk of developing a tumor than people abusing just one ${ }^{8,9}$. Additional risk factors for developing spinocellular carcinoma may be poor dental hygiene or missing teeth ${ }^{10,11}$. Using a mouthwash with a high alcohol content is a possible, though not proven, risk factor ${ }^{10,11}$. The presence or absence of metastasis in the cervical lymph nodes is an important predictor 
of the prognosis and survival of patients with orofacial tumors. A one-sided lymph node metastasis reduces the survival rate by about $50 \%$ and bilateral metastasis by another $25 \%$ (ref. $^{12-15}$ ). A major risk is occult metastases, the occurrence of which is closely related to the methods used for the examination of the cervical lymph nodes, with higher sensitivity of the used imaging method reducing the risk of the occurrence of occult metastasis ${ }^{16}$. The most common methods of examination of the cervical metastases include physical examination (PE), ultrasonography (US), computed tomography (CT) or magnetic resonance imaging (MRI) or modern methods such as fine needle aspiration cytology (FNAC) or positron emission tomography (PET). While the first three methods are relatively cheap and widely available, MRI, despite being also widely available, is much more expensive and FNAC or PET, although they can provide better results, combine the disadvantages of the high costs and limited accessibility in everyday practice. According to the recommendations of the Royal Society of Radiology, only CT is recommended for the initial staging of the tumor in the oral cavity, however MRI or PET are also mentioned as additional methods. US is however not mentioned in these guidelines et al. ${ }^{17}$. In this retrospective study, we aimed to evaluate the diagnostic accuracy of the methods used in our hospital (i.e., physical examination, ultrasonography and computed tomography) and to investigate whether a combination of some or all of those relatively inexpensive methods improves the diagnostic accuracy of metastases in the cervical lymph nodes.

\section{METHODS}

Our study group comprised patients who were treated for spinocellular carcinoma (verified histopathologically) of the oral cavity between 2011 and 2018 at the Department of the Oral and Maxillofacial Surgery at the
University Hospital Ostrava and who had undergone examinations by all three investigated methods (PE, US, CT) with subsequent block neck dissection (BND) (Fig. 2) and histological examination of the removed lymph nodes. The individual neck spaces I-V (ref. ${ }^{12,13}$ ) were after the excision marked in a way allowing the pathologist to evaluate metastases in the individual parts. The results of the examination methods were subsequently compared to the results of the histopathological examination and statistically evaluated. The research group comprised altogether 57 patients, 25 females and 32 males, mean age 59 years (33-85 years). The standard physical examination included palpation and visual evaluation of the site, size, consistency, mobility and character of the indurated surface. Imaging methods distinguished between benign (oval shape, below $10 \mathrm{~mm}$ in the long axis, echogenic hilum and perinodal fat tissue) and suspected (enlarged over $10 \mathrm{~mm}$, round shape, extranodal extension, or necrotic changes) lymph nodes $^{18,22}$. Ultrasonography examinations were performed using Aloka ProSound 3500 (Ohio, USA) or GE Logiq S7 (Massachusetts, USA) instruments. Linear probes with frequencies 3.5-13 MHz were used in the mode of soft tissue detection; parameters of the examination were customized by the personnel according to current acoustic conditions in the tissues. CT examinations utilized multidetector scanners Siemens Definition AS+ or Definition AS (Munich, Germany). The scanning was performed in thin collimation with image reconstruction in the soft tissue filter. In each patient, the findings were evaluated both in the native image and after intravenous application of appropriate quantity of iodine-containing contrast medium. In our hospital, a dedicated team consisting of an experienced oncologist, maxillofacial surgeon, and radiologist specialized in the imaging techniques of the head and neck was formed for evaluation of the nodal metastases. A clinical classification (cTNM) of the tumor was performed by this multidisciplinary team after the physical examination and imaging methods. As the inclusion

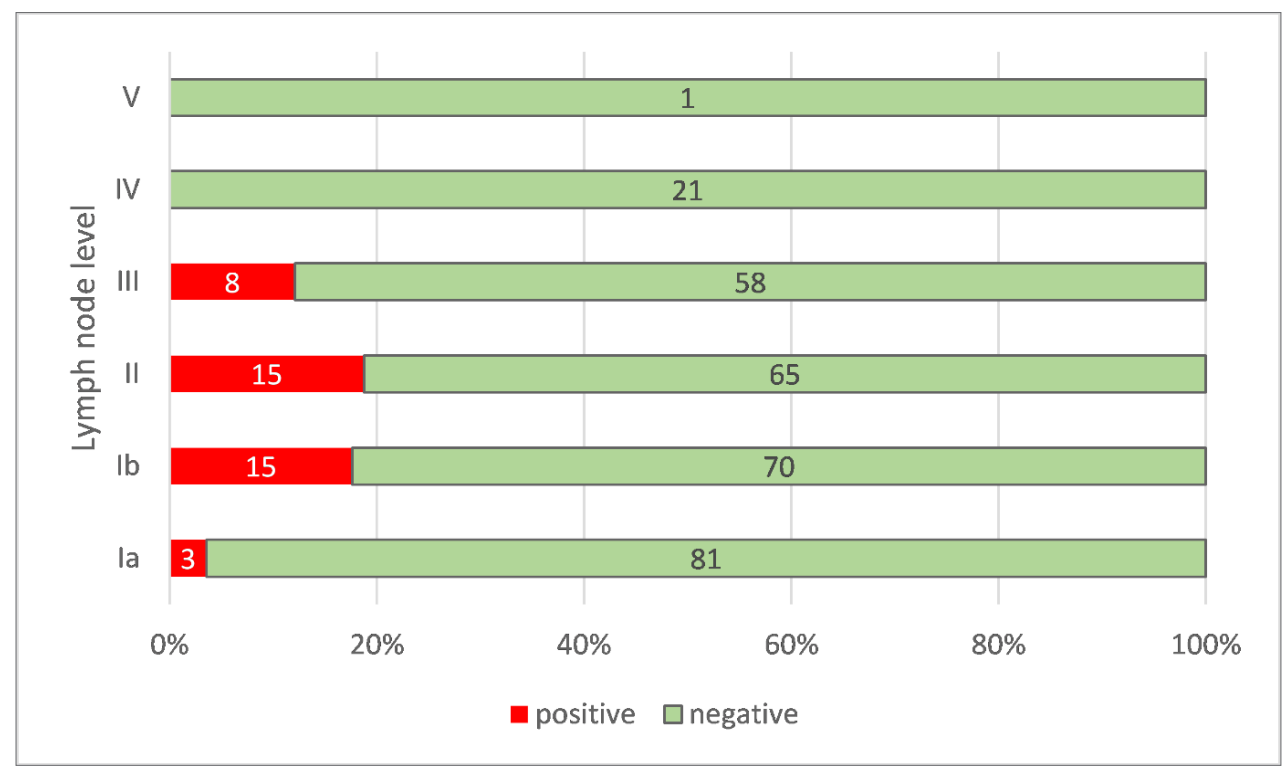

Fig. 1. Occurrence of affected lymph nodes in relation to unaffected ones in the individual neck spaces according to the histopathological findings. 
Table 1. Comparison of the results of individual methods of clinical examination and their combinations to the results of histopathological examination.

\begin{tabular}{lrrrrrrr}
\hline & PE & US & CT & PE+US & PE+CT & CT+US & PE+CT+US \\
\hline True positives & 16 & 29 & 26 & 31 & 30 & 35 & 36 \\
False positives & 23 & 71 & 66 & 75 & 73 & 99 & 102 \\
True negatives & 273 & 225 & 230 & 221 & 223 & 197 & 194 \\
False negatives & 26 & 13 & 16 & 11 & 337 & 7 & 6 \\
Total & 337 & 337 & 337 & 337 & 337 & 337 \\
\hline
\end{tabular}

PE - physical examination; US - ultrasonography; CT - computed sonography

Table 2. Standard test characteristics of individual clinical examination methods and their combinations.

\begin{tabular}{llcccc}
\hline & & Sensitivity & Specificity & PPV & NPV \\
\hline Individual methods & PE & 38.1 & 92.2 & 41.0 & 91.3 \\
& US & 69.0 & 76.0 & 29.0 & 94.5 \\
& CT & 61.9 & 77.7 & 28.3 & 93.5 \\
2-way combination & PE+US & 73.8 & 74.7 & 29.2 & 95.3 \\
& PE+CT & 71.4 & 75.3 & 29.1 & 94.9 \\
3-way combination & US+CT & 83.3 & 66.6 & 26.1 & 96.6 \\
\hline
\end{tabular}

PPV - positive predictive value; NPV - negative predictive value; PE - physical examination; US - ultrasonography; CT - computed sonography

criteria imply, all patients in our group underwent BND with subsequent histopathological evaluation (pTNM). The results were evaluated based on the presence of malignancy in individual cervical spaces. Confusion tables for individual examination methods as well as their combinations were subsequently prepared using histopathological findings as true data and sensitivities, specificities, positive and negative predictive values were calculated. If there was a suspention for malignity based on at least one examination, the lymph node was considered as malignant-i.e., clinically negative nodes were only those without any suspicion in any method. Patients signed informed consent with participation in the study.

\section{RESULTS}

There were 57 patients included in the study. The most common site of the primary carcinoma in our study was the floor of the oral cavity (30\%) closely followed by the tongue $(28 \%)$. Most of the tumors in our group were clinically classified as cT2 (30 patients; $53 \%$ ) which was in good accordance with the histopathological classification which determined 28 patients $(49 \%)$ to be in the T2 stage. We also evaluated the occurrence of the affected lymph nodes in the individual neck spaces - Ia, Ib, II, III, IV, a $\mathrm{V}$. The most frequently affected nodes were in the Ib and II spaces, see Fig. 1. Altogether, 684 neck spaces underwent all clinical examinations (PE, US and CT); 337 of those (49.3\%) were subsequently evaluated histologically. The statistical evaluation was assessed as follows: results positive in clinical examination but negative in histological verification were evaluated as positive, results positive in clinical examination but negative in histological verification were evaluated as false positive, results negative in clinical examination but positive in histological verification were evaluated as false negative. Table 1 shows the results of comparison between individual methods of clinical examination (or their combinations) and results of the histopathological examination. Table 2 presents standard test characteristics used for the evaluation of the individual clinical examination methods and their combinations related to the results of histopathological examination used as true data.

\section{DISCUSSION}

The degree of metastatic spread reflects the tumor aggressiveness and constitutes an important prognostic factor in relation to survival ${ }^{19}$. Nevertheless, is it not easy to clinically detect metastatic nodal involvement, because they can be mistaken for reactive inflammatory changes ${ }^{20}$. Even small lymph nodes clinically indistinguishable from healthy ones can contain malignant cells (micrometastases) that are only detectable during histopathological examination $^{20}$. From this perspective, it might appear reasonable to perform block neck dissection (BND) in all cases of the spinocellular carcinoma. On the other hand, any unnecessary BND increases the patient morbidity and risk of post-operative complications. Hence, an accurate examination method would be very valuable 


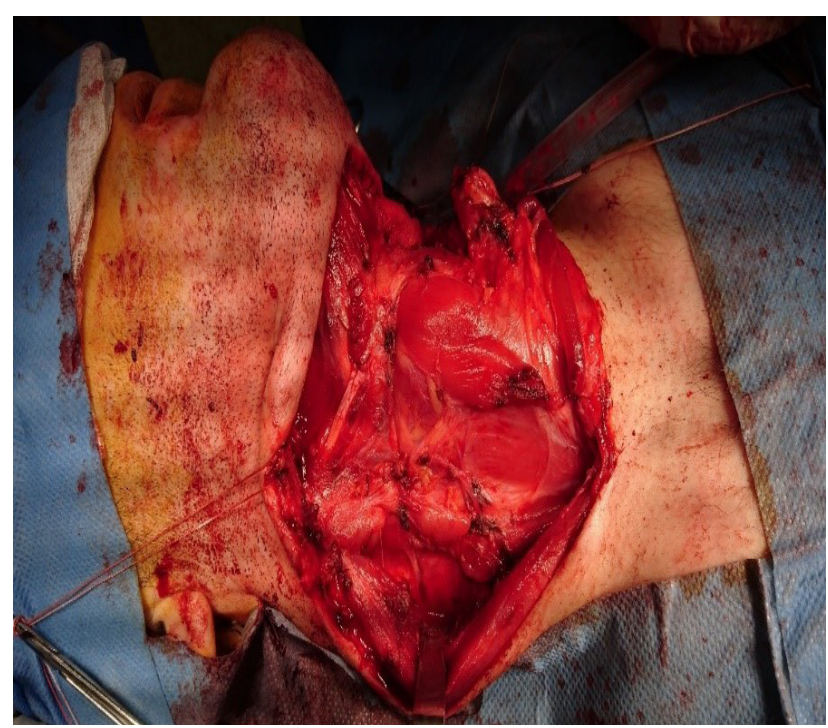

Fig. 2. Radical neck dissection on left side of the neck.

in identification of patients benefiting from BND (ref. ${ }^{21}$ ). Although modern imaging methods such as PET/CT or FNAC became available over the last decades ${ }^{11,22}$, physical examination along with US and CT, along with MRI, which is however significantly more expensive, remain the principal examination methods. In this study, we have investigated the accuracy of these three methods (PE, US, $\mathrm{CT}$ ) alone as well as of their combinations for detection of malignant nodes. All are relatively cheap and available but their individual sensitivity is quite low. The sensitivity of the physical examination alone in our group was $38 \%$, which means that this method would fail to capture most malignant nodes. From this point of view, we cannot recommend using this method alone. Comparing CT and US, the results were similar, capturing $69 \%$ and $62 \%$ of malignant nodes, respectively. However, the combination increased the sensitivity to $83 \%$ and a combination of all three methods to $86 \%$. Hence, a combination of all three methods shows the best results, however $14 \%$ of nodal metastases remains undetected. The good news is the high negative predictive value of approx. $97 \%$ for the combination of both US+CT and US+CT+PE. The high number of false positives is attested by the low positive predictive value (below 30\%) and specificity (below 70\%). This result cautions us that the combination is not sufficient to indicate a patient to BND as it often does. From this perspective, it appears that we should not perceive these methods and their combination as a diagnostic method but rather a relatively cheap Tier I screening battery to select patients for subsequent more expensive examinations such as PET, MRI or FLIR. It might still be beneficial to repeat at least the two cheapest methods associated with no radiation risk 1-2 months after the original examination, even in patients who turned out negative result during the original examination to minimize the risk of micrometastases, which could be presented at the time of the original examination. A study by Shetty et al. ${ }^{22}$ investigated, as did our study, the performance of palpation, ultrasonography and $\mathrm{CT}$ for detection of metastatic cervical lymph nodes. Their results of physical examinations were almost identical to ours (36.6\%), however the results for US (54.5\%) and CT $(31.8 \%)$ were poorer than ours. Rottey et al. ${ }^{23}$ performed a similar study with the addition of US-guided FNAC. The results of individual methods were not unlike ours, with the sensitivity of PE, US, FNAC and CT being $48.7 \%$, $65.8 \%, 86.7 \%$ and $52.5 \%$ and specificities in the same order being $95.5 \%, 83.0 \%, 87.5 \%$, and $83.6 \%$, respectively. Apparently, FNAC provided the best results from that set of studies. The sensitivity was however no better that our combined battery, although the specificity was markedly better. We must bear in mind that FNAC is, unlike the investigated methods, an invasive method. FNAC could be a good option in preselected patient group where enlarged nodes are detected or where there are still doubts after the initial examination. A metaanalysis by Liao et al. compared several studies on detection of cervical lymph node metastases in patients with head and neck tumors ${ }^{24}$. Eight studies meeting their selection criteria for US examination, 7 studies for CT, 6 studies for MRI and 11 studies for PET were included in the metaanalysis. Apart from a lower CT sensitivity, the mean sensitivity and specificity of all investigated methods were similar among themselves, sensitivity of the individual methods were also similar to results of our study, although reported specificity were higher. The sensitivity was $65 \%$ for US, $52 \%$ for CT, $65 \%$ for MRI and $66 \%$ for PET/CT, and the specificity $78 \%$ for US, $81 \%$ for CT and MRI and $87 \%$ for PET respectively. Many other studies on individual methods have been published, reviewed e.g. by Blatt et al. ${ }^{25}$ and Sarrion-Perez ${ }^{26}$ with varying results. Detailed review is not within the scope of this paper and we would like to refer this review to interested readers. We are not aware of any study investigating the performance of a battery of examination methods such as that presented here.

\section{CONCLUSIONS}

Our study confirmed that individual widely available and relatively cheap imaging methods provide similar sensitivities and specificities for detection of potential cervical metastases of spinocellular carcinoma. Although the contribution of physical examination to the performance of a US+CT combination is relatively small, we should bear in mind that it is still the basic examination method that should be performed in every patient, so its inclusion in the battery of tests is reasonable. The PE+US+CT combination yielded an $86 \%$ sensitivity and $97 \%$ NPV, however the number of false positive detections was quite high. From this point of view, such a combination appears to be, due to its relatively low price, a suitable screening method useful for preselecting patients in need of additional, more expensive, imaging methods. Still, with a sensitivity of $86 \%$, we also recommend further examination of patients at least using physical examination and US as our battery does not lead to capture of all metastases at the time of the original examination. We also believe that our hospital multidisciplinary team, including a maxillofacial surgeon, radiologist and oncologist, who are specialized in head and neck cancer, is an advantage. 
Acknowledgement: This research was supported by Ministry of Health of the Czech Republic, grant nr. NV1908-00383. All rights reserved. This research was supported by Ministry of Health, Czech Republic - conceptual development of research organization (FNOs/2016).

Author contributions: JS: data analysis, manuscript writing; PH: study design, manuscript writing; TJ: participated in data analysis and wrote specific part of manuscript; ZC: participated in data analysis and wrote specific part of manuscript; KR: participated in data analysis and wrote specific part of manuscript; MK: data collection; JC: participated in study design and coordination; JS: carried out a critical review of the manuscript; ML: statistical analysis. All authors read and approved the final manuscript. Conflict of interest statement: The authors state that there are no conflicts of interest regarding the publication of this article.

\section{REFERENCES}

1. Ferlay J, Soerjomataram I, Ervik M, Dikshit R, Eser S, Mathers C, Rebelo M, Parkin DM, Forman D, Bray, F., Cancer incidence and mortality worldwide: sources, methods and major patterns in GLOBOCAN 2012. Int J Cancer 2015;136(5):E359-E386.

2. Gandini S, Botteri E, lodice S, Boniol M, Lowenfels AB, Maisonneuve P, Boyle P Tobacco smoking and cancer: a meta-analysis, Int J Cancer 2008;122(1):155-64.

3. Hashibe M, Boffetta P, Zaridze D, Shangina O, Szeszenia - Dabrowska $\mathrm{N}$, Mates D, Janout V, Fabiánová E, Bencko V, Moullan N, Chabrier A, Hung R, Hall j, Canzian F, Brennan P. Evidence for an important role of alcohol- and aldehyde-metabolizing genes in cancers of the upper aerodigestive tract. Cancer Epidemiol Biomarkers Prev 2006;15(4):696-703.

4. Hashibe M, Brennan P, Benhamou S, Castellsague X, Chen C, Curado MP, Dal Maso L, Daudt AW, Fabianova E, Fernandez L, Wünsch-Filho V, Franceschi S, Hayes RB, Herrero R, Koifman S, La Vecchia C, Lazarus P, Levi F, Mates D, Matos E, Menezes A, Muscat J, Eluf-Neto J, Olshan AF, Rudnai P, Schwartz SM, Smith E, Sturgis EM, Szeszenia-Dabrowska N, Talamini R, Wei Q, Winn DM, Zaridze D, Zatonski W, Zhang ZF, Berthiller J, Boffetta P. Alcohol drinking in never users of tobacco, cigarette smoking in never drinkers, and the risk of head and neck cancer: pooled analysis in the International Head and Neck Cancer Epidemiology Consortium. J Natl Cancer Inst 2007;99(10):777-89.

5. Boffetta P, Hecht S, Gray N, Gupta P, Straif K. Smokeless tobacco and cancer. Lancet Oncol 2008;9(7):667-75.

6. Blot WJ, McLaughlin JK, Winn DM, Austin DF, Greenberg RS, PrestonMartin S, Bernstein L, Schoenberg JB, Stemhagen A, Fraumeni JF Jr. Smoking and drinking in relation to oral and pharyngeal cancer. Cancer Res 1988; 48(11):3282-7.

7. Tuyns AJ, Estève J, Raymond L, Berrino F, Benhamou E, Blanchet F, Boffetta P, Crosignani P, del Moral A, Lehmann W Cancer of the larynx/hypopharynx, tobacco and alcohol: IARC international casecontrol study in Turin and Varese (Italy), Zaragoza and Navarra (Spain), Geneva (Switzerland) and Calvados (France). Int J Cancer 1988;41(4):483-91.

8. Hashibe M, Brennan P, Chuang SC, Boccia S, Castellsague X, Chen C, Curado MP, Dal Maso L, Daudt AW, Fabianova E, Fernandez L, Wünsch-Filho V, Franceschi S, Hayes RB, Herrero R, Kelsey K, Koifman S, La Vecchia C, Lazarus P, Levi F, Lence JJ, Mates D, Matos E, Menezes A, McClean MD, Muscat J, Eluf-Neto J, Olshan AF, Purdue M, Rudnai P, Schwartz SM, Smith E, Sturgis EM, Szeszenia-Dabrowska N, Talamini R, Wei Q, Winn DM, Shangina O, Pilarska A, Zhang ZF, Ferro G, Berthiller J, Boffetta P. Interaction between tobacco and alcohol use and the risk of head and neck cancer: pooled analysis in the International Head and Neck Cancer Epidemiology Consortium. Cancer Epidemiol Biomarkers Prev 2009;18(2):541-50.
9. Mayne ST, Morse DE, Winn DM. Cancers of the Oral Cavity and Pharynx. In: Schottenfeld D, Fraumeni JF Jr., Cancer Epidemiology and Prevention. $3^{\text {rd }}$ ed. New York: Oxford University Press, 2006.

10. Guha N, Boffetta $P$, Wünsch Filho V, Eluf Neto J, Shangina O, Zaridze D, Curado MP, Koifman S, Matos E, Menezes A, Szeszenia-Dabrowska N, Fernandez L, Mates D, Daudt AW, Lissowska J, Dikshit R, Brennan $P$. Oral health and risk of squamous cell carcinoma of the head and neck and esophagus: results of two multicentric case-control studies. Am J Epidemiol 2007;166(10):1159-73.

11. Hodder SC, Evans RM, Patton DW, Silvester KC Ultrasound and fine needle aspiration cytology in the staging of neck lymph nodes in oral squamous cell carcinoma. Br J Oral Maxillofac Surg 2000,38(5):430-6.

12. Sarvanan K, Bapuraj JR, Sharma SC, Radotra BD, Khandelwal N, Suri $S$ (2002) Computed tomography and ultrasonographic evaluation of metastatic cervical lymph nodes with surgico-clinicopathologic correlation. J Laryngol Otol 2002;116(3):194-9.

13. D'Souza O, Hasan S, Chary G, Ravi Hoisala V, Carrea M (2003) Cervical lymph node metastases in head and neck malignancy- A clinical / ultrasonographic/histopathological comparative study. Indian J Otolaryngol Head Neck Surg 2003;55(2):90-3.

14. Haberal I, Celik H, Goçmen H, Akmansu H, Yoruk M, Ozeri C. Which is important in the evaluation of metastatic lymph nodes in head and neck cancer: palpation, ultrasonography, or computed tomography? Otolaryngol Head Neck Surg 2004;130(2):197-201.

15. Atula TS, Grenman R, Varpula MJ, Kurki TJ, Klemi PJ (1996) Palpation, Ultrasound and Ultrasound -Guided Fine Needle Aspiration Cytology in the assessment of cervical lymph node status in Head and Neck cancerpatients. Head Neck 1996;18(6):545-51.

16. van den Brekel MW, Castelijns JA, Snow GB (1998) Diagnostic evaluation of the neck. Otolaryngol Clin North Am 1998;31(4):601-20.

17. Olliff J, Richards P, Connor S, Wrong WL, Beale T, Madani G. Head and neck cancers. Recommendations for cross-sectional imaging in cancer management. Second edition. London: The Royal Collage of Radiologict, 2014, p. 14.

18. van den Brekel MW, Stel HV, Castelijns JA, Nauta JJ, van der Waal I, Valk J, Meyer CJ. Snow GB. Cervical lymph node metastasis: assessment of radiologic criteria. Radiology 1990;177(2):379-84.

19. Barrera JE, Miller ME, Said S, Jafek BW, Campana JP, Shroyer KR. Detection of occult cervical micrometastases in patients with head and neck squamous cell cancer. Laryngoscope 2003;113(5):892-6.

20. Takes RP, Righi P, Meeuwis CA, Manni JJ, Knegt P, Marres HA, Spoelstra HA, de Boer MF, van der Mey AG, Bruaset I, Ball V, Weisberger E, Radpour S, Kruyt RH, Joosten FB, Laméris JS, van Oostayen JA, Kopecky K, Caldemeyer K, Henzen-Logmans SC, Wiersma-van Tilburg JM, Bosman FT, van Krieken JH, Hermans J, Baatenburg de Jong RJ. 1998) The value of ultrasound with ultrasound-guided fine needle aspiration biopsy compared to computed tomography in the detection of regional metastasis in the clinically negative neck. Int J Radiat Oncol Biol Phys 1998;40(5):1027-32.

21. Deepthi Shetty, Bhushan V. Jayade, Shyamsundar K. Joshi, K. Gopalkrishnan. Accuracy of Palpation, Ultrasonography, and Computed Tomography in the Evaluation of Metastatic Cervical Lymph Nodes in Head and Neck Cancer. Indian J Dent 2015;6(3):121-4.

22. Sorin M. Dudea, Manuela Lenghel, Carolina Botar-Jid, Dan Vasilescu, Magdalena Duma Ultrasonography of superficial lymph nodes: benign vs. Malignant. Med Ultrason 2012;14(4):294-306.

23. Liao, Li-Jen, Wu-Chia Lo, Wan-Lun Hsu, Chi-Te Wang, Mei-Shu Lai. Detection of Cervical Lymph Node Metastasis in Head and Neck Cancer Patients with Clinically NO Neck a Meta-Analysis Comparing Different Imaging Modalities. BMC Cancer 2012;12:236.

24. Rottey S, Petrovic M, Bauters W, Mervillie K, Vanherreweghe E, Bonte K, Van Belle S, Vermeersch H. Evaluation of metastatic lymph nodes in head and neck cancer: A comparative study between palpation, ultrasonography, ultrasound-guided fine needle aspiration cytology and computed tomography. Acta Clin Belg 2006;61(5):236-41.

25. Blatt $S$, Ziebart T, Krüger M, Pabst AM, Diagnosing oral squamous cell carcinoma: How much imaging do we really need? A review of the current literature. J Craniomaxillofac Surg 2016;44(5):538-49.

26. Sarrión MG, Bagán JV, Jiménez $Y$, Margaix $M$, Marzal C, Utility Of Imaging Techniques In The Diagnosis Of Oral Cancer. J Craniomaxillofac Surg 2015;43(9):1880-94. 